\title{
DESIGN OF A COMPUTER- SUPPORTED COOPERATIVE ENVIRONMENT FOR SMALL AND MEDIUM ENTERPRISES
}

\author{
Ana Paula Freitas Mundim \\ University of São Paulo \\ Engineering School of São Carlos \\ Av. Dr. Carlos Botelho, 1465 \\ 13560350 São Carlos SP BRAZIL \\ amundim@sc.usp.br \\ Carlos Frederico Bremer \\ University of São Paulo \\ Engineering School of São Carlos \\ Av. Dr. Carlos Botelho, 1465 \\ 13560350 São Carlos SP BRAZIL \\ bremer@sc.usp.br
}

\begin{abstract}
The quick development of new information technologies and the enterprises tendency to concentrate on their core competencies, aiming to become agile to survive in the competitive actual market, increase the number of co-operations among enterprises. In this context, Virtual Enterprises (VE) are an appropriate alternative and competitive advantage to Small and Medium Enterprises (SMEs). VEs can be formed inside Virtual Organisations (VOs), which are networks of potential partners (enterprises). However, VEs become more feasible by means of a systematic use of modern information technologies, due to a significant reduction on transaction costs. This paper describes a cooperative environment supported by computer, in order to enable and optimise the participation of SMEs in VOs.
\end{abstract}

\section{INTRODUCTION}

Various factors thrive to the growing of co-operations among enterprises, as the quick technological transformations, the process of globalization and the tendency to concentrate on core competencies (Hamuel \& Prahalad, 1994). That is, in view of increased international competition, enterprises are investigating new integration processes to become agile and to maintain their competitive position.

The focus on core competencies requires that the enterprises co-operate among themselves to offer complete products or services to the customer market. 
This scenario opens new perspectives to the business increase of Small and Medium Enterprises (SMEs), as they have an structure more agile and so, more adequate to cope with the characteristics presented above.

In this business environment, SMEs face the challenge of finding an organization model which enable the exploration of opportunities, even global, considering their limited resources and without the exposure to the risk of direct investment. Virtual Enterprises (VEs) and their form of organization based on co-operation and competitiveness can be assumed adequate to fulfill these requirements and also, support the formation of high technological based enterprises (Bremer, 1996).

VEs are mainly based on the integration of competencies among independent enterprises, providing a product or a service, which could not be offered in time and with an attractive cost by none of the cooperation partners alone. VEs may be formed within Virtual Organizations (VOs), which are then, a stable network of potential partners (enterprises) of a VE. That is, one or various VEs are a consequence or a result of a VO.

This approach is based strongly in the intense use of advanced computer services of communication and information. The intense use of modern information technology enables a significant reduction on transaction cost, making the VEs economically viable (Picot et al., 1996). However, your effectuation depends fundamentally on organizational aspects. Then, in a VE, the organization and the intense use of information and communication technologies are dependent and associated.

Nevertheless, to achieve the benefits that the use of modern information and communication technologies can proportionate, enterprises have to know when, where, how and which technology they should use. The aim of this paper is to present the design of a computer-supported co-operative environment for SMEs participate in VOs, whose objective is to permit them to take profit of the information technology use optimization. The environment was designed based on a reference model of VOs, which describes the main work processes and enables the identification of the communication and group work requirements of distributed teams. So, first a description of this VO model is given. Afterwards, the information technologies considered in this environment are presented and classified, in order to describe the co-operative environment itself. Finally, an exemplification scenario of the proposed environment is presented.

\section{FRAMEWORK FOR GLOBAL VIRTUAL BUSINESS}

Extending the virtualization potentialities, SMEs can be inserted in global cooperations. The framework for Global Virtual Business was developed to explain how a Global Virtual Enterprise (GVE) can be formed, run and dissolved (Bremer et al., 1999). The GVE can exploit the advantages of being global using local competencies.

This framework is constituted of three business entities: the Virtual Industry Cluster (VIC), the Virtual Enterprise Broker (VEB) and the Virtual Enterprise (VE). The VIC is a aggregation of enterprises from diverse industries, with well defined and focused competencies, whose purpose is to gain access to new markets and business opportunities by leveraging their resources. The VEB enables the creation 
of VEs through use of the services provided by the VICs. A VE is a temporary network of independent enterprises, linked by information technology, that share competencies, infrastructure and business processes, with the purpose to fulfil a specific market requirement (Byrne, 1993). It may be formed within a VO, which is then, the aggregation of the VIC and a VEB.

In the framework (Figure 1), the VE is created when an opportunity for business can be exploited by the VEB through the selection of the appropriate competencies from members of a VIC. A VEB will look for business opportunities around the world or will receive requests for specific products/services. In order to satisfy this demand, the VEB will search partners in VICs for the best combination of competencies that, as a whole, should meet the customer requirements of a product or service. The success of the VE depends on the VEB abilities to ensure the integration of competencies and the co-operation among partners. Moreover, the VIC manager has to configure the adequate infrastructures (physical, information, legal and social/cultural) to support the operation/dissolution of the VE. Once a member of a VIC is selected it becomes a partner of a specific VE.

It is important to highlight that the Global Virtual Business Framework proposes the profit improvement of its members, by means of resources, processes and knowledge (skills) leveraging, and not by imposing to them the direction to be followed.

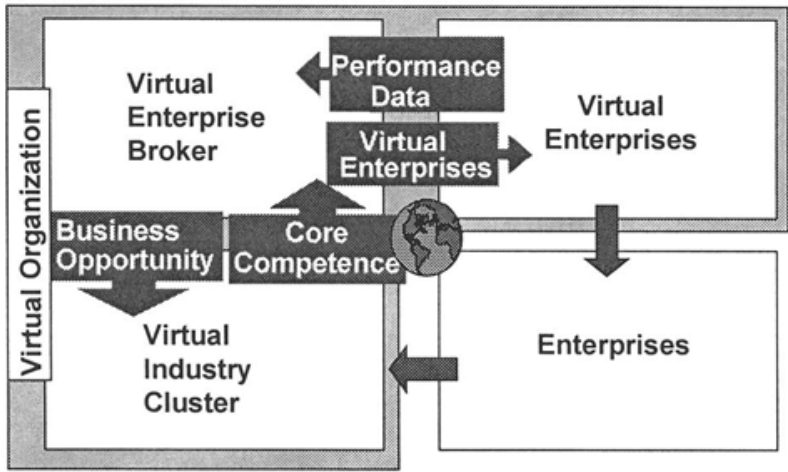

Figure 1 - Framework for Global Virtual Business Adapted from (Bremer et al., 1999)

Another interesting issue to be considered is that not all the VO or VIC members will join into a VE. Only the necessary competencies will take part on it, and the profit - or losses - distribution will not be equally divided, but they must follow the individual commitment and investment of each partner, towards the several interests involved, like profit gain, marketing, knowledge improvement and development.

\section{WORKGROUP TOOLS}

The design of this computer-supported co-operative environment considered only the information technologies which would have quick acceptance (in terms of low costs related to the benefits it can proportionate, easy training and implementation) by the SMEs and which would support the communication infrastructure defined. 
In this context, the chosen workgroup tools can be analyzed and classified according to two different characteristics: time processing (synchronous or asynchronous services) and focus (personal communication or common working material) (Maab, 1990). Synchronous services enable the simultaneous work of the participants of a session (or conference). Asynchronous services are directed for the work outside the session (not simultaneously). Besides that, the functions of these services can be divided into the aspects of: personal communication or the work/ transfer of a common information object. In this way, a videoconference is a simultaneous work, for personal communication, when the data transfer supports an asynchronous exchange of a common information object (Figure 2).

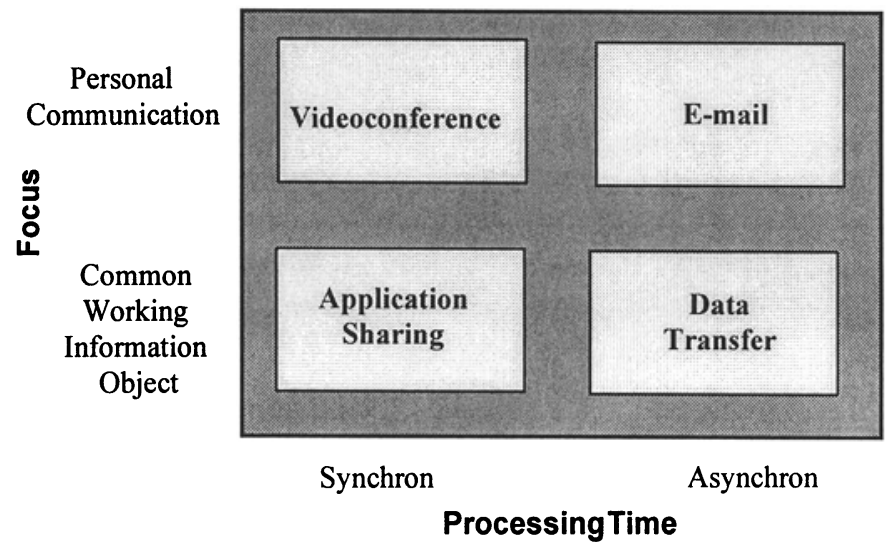

Figure 2 - Classification of Work Group Tools Adapted from (Maab, 1990)

However, it is important to notice that this classification is not rigid, as the services can assume various functions depending on user requirements or the developers applicabilities. For example, e-mail and data transfer can not be precisely divided because many e-mail systems aggregate the functionality of data transfer. Another case, is when videoconference is used together with the application sharing for the discussion of a problem.

Another highlight is that this project design have not considered other workgroup tools like workflow systems and electronic group agenda. This is not only because of the focus on simple technological solutions for SMEs, but also, because the functionality of these systems is more adequate to cyclical and stable processes, in general inside of an enterprise. However, research advances of these systems can be already found in the dynamic context of virtual distributed environments (Camarinha-Matos \& Lima, 1998).

With the workgroup tools selected and their functionalities classified, the cooperative environment can be designed, based on the main processes of a VO (Framework for Global Virtual Business). 


\section{COMPUTER CO-OPERATIVE ENVIRONMENT}

One of the main points in a computer environment project for distributed group work is the analysis of the work processes and the requirements of communication and group work of the teams (Olson \& Teasley, 1996). Then, the first step of the cooperative environment design was the Global Virtual Business framework processes mapping. The description of these processes enabled the specification of the main action types, which require and permit computer support in the distributed environment of a VO.

Based on these types of communication and co-operative work actions, a correlation of this classification to examples of involvement required by each action was elaborated. Only after this relation, a definition of which workgroup tools and which communication infrastructure would support these necessities was reached.

The actions types contained in the environment design try to cover all phases of a distance co-operative environment: implementation, production and sustain of distributed workflow (Hardwick, 1997). These types of action also constitute the more utilized co-operative functionalities (Coleman, 1996 ; Colaborative strategies, 1996; Creighton \& Adams, 1998).

The computer co-operative environment is composed of four modules (Table 1), which specify the four main action types of a distributed co-operative environment and their kind of involvement required. These lasts relate to the workgroup tools to be utilized - e-mail, data transfer, videoconference and application sharing.

The Generation of New Ideas/Approaches is the first action, which requires, for instance, appointment with an external expert about a critical question and/or a section of questions and answers among the group members. These requirements can be fulfilled by the workgroup tools: data transfer, videoconference and application sharing. Which can proportionate, for example, discussion of the approach by means of audio and videoconference and the points can be detailed in real time on the same notepad. These tools need some specific characteristics of group work, like: flexibility, autonomy, training to work co-operatively at distance and adaptation to a constant changing environment.

The second type of action is Project Planning which needs certain types of involvement as: exchange of information and files to correction or approve and simple exchange of messages in order to reach a consensus on specific points. These needs can be solved by means of e-mail and data transfer, which can leads to: simple personal communication to define plans and quick and cheap exchange of a great amount of data, like digitized models and agendas, for example. These workgroup tools are of easy training, implementation and use, not requiring any profound modification or adaptation of the enterprise.

Information Exchange is the third action that needs, for example, contact to external people about simple doubts and exchange of information/data specific of a same project or of different projects. These requires can be fulfilled by means of email and data transfer, which can offer the benefits of quick and easy exchange of communication and information, and access to physically distributed people in order to uniform information and knowledge, for example. These tools as described before are of simple adaptation. 
Table 1 - Computer-Supported Co-operative Environment for SMEs

\begin{tabular}{|c|c|c|c|}
\hline $\begin{array}{c}\text { Action Type } \\
\text { in a } \\
\text { Distributed } \\
\text { Environment }\end{array}$ & $\begin{array}{l}\text { Examples of Required } \\
\text { Kind of Involvement }\end{array}$ & $\begin{array}{c}\text { Workgroup } \\
\text { Tools }\end{array}$ & $\begin{array}{l}\text { Technological } \\
\text { Benefits }\end{array}$ \\
\hline $\begin{array}{l}\text { Generation of } \\
\text { New Ideas/ } \\
\text { Approaches }\end{array}$ & $\begin{array}{l}\text { - Appointment with an } \\
\text { external expert about a } \\
\text { critical question. } \\
\text { - Section of questions } \\
\text { and answers among the } \\
\text { group members. }\end{array}$ & $\begin{array}{l}\text { - Data Transfer } \\
\text { - } \\
\text { Videoconference } \\
\text { - Application } \\
\text { Sharing }\end{array}$ & $\begin{array}{l}\text { - Discussion of the } \\
\text { approach by means } \\
\text { of audio and } \\
\text { videoconference. } \\
\text { - The points can be } \\
\text { detailed in real time } \\
\text { on the same notepad. }\end{array}$ \\
\hline $\begin{array}{l}\text { Project } \\
\text { Planing }\end{array}$ & $\begin{array}{l}\text { - Exchange of } \\
\text { information and files to } \\
\text { correction or approve. } \\
\text { - Simple exchange of } \\
\text { messages in order to } \\
\text { reach a consensus on } \\
\text { specific points. }\end{array}$ & $\begin{array}{l}\text { - E-mail } \\
\text { - Data Transfer }\end{array}$ & $\begin{array}{l}\text { - Simple personal } \\
\text { communication to } \\
\text { define plans. } \\
\text { - Quick and cheap } \\
\text { exchange of a great } \\
\text { amount of data, like } \\
\text { digitized models and } \\
\text { agendas. } \\
\end{array}$ \\
\hline $\begin{array}{l}\text { Information } \\
\text { Exchange }\end{array}$ & $\begin{array}{l}\text { - Contact to external } \\
\text { people about simple } \\
\text { doubts. } \\
\text { - Exchange of } \\
\text { information/data } \\
\text { specific of a same } \\
\text { project or of different } \\
\text { projects. }\end{array}$ & $\begin{array}{l}\text { - E-mail } \\
\text { - Data Transfer }\end{array}$ & $\begin{array}{l}\text { - Quick and easy } \\
\text { exchange of } \\
\text { communication and } \\
\text { information } \\
\text { - Access to } \\
\text { physically } \\
\text { distributed people in } \\
\text { order to uniform } \\
\text { information and } \\
\text { knowledge. } \\
\end{array}$ \\
\hline $\begin{array}{l}\text { Problems } \\
\text { Solving }\end{array}$ & $\begin{array}{l}\text { - Discussion of complex } \\
\text { aspects, like a product } \\
\text { drawing. } \\
\text { - Necessity of more } \\
\text { sensibility involvement } \\
\text { to the efficient } \\
\text { understanding of a } \\
\text { problem and its possible } \\
\text { solutions. }\end{array}$ & $\begin{array}{l}\text { - Data Transfer } \\
\text { - } \\
\text { Videoconference } \\
\text { - Application } \\
\text { Sharing }\end{array}$ & $\begin{array}{l}\text { - Group work on the } \\
\text { same external } \\
\text { application, without } \\
\text { the necessity to have } \\
\text { it inside the } \\
\text { machine. } \\
\text { - Visualization on } \\
\text { real time of the } \\
\text { partner or prototype, } \\
\text { inclusive with } \\
\text { exchange of audio. }\end{array}$ \\
\hline
\end{tabular}


The fourth and last type of action is the Problems Solving which requires some kind of involvement as: discussion of complex aspects, like a product drawing and necessity of more sensibility involvement to the efficient understanding of a problem and its possible solutions. These needs can be solved by the workgroup tools: data transfer, videoconference and application sharing. Which can proportionate, for example, group work on the same external application, without the necessity to have it inside the machine and visualization on real time of the partner or prototype, inclusive with exchange of audio. These computer tools, as highlighted in the first type of action, require some attention to adaptation.

The co-operative environment is inserted in the context of a distributed environment, where there are a series of communication problems related to cooperative work. These problems affect the four types of action considered. Nevertheless, the aim of the proposed co-operative environment is to solve these problems, by means of determining which workgroup tools and communication infra-structure are needed and that should be used in a specific action of co-operative work.

Following, the communication infrastructure is defined in order to support all the workgroup tools by means of a standard protocol.

\subsection{Communication Infrastructure}

A communication infrastructure developed for the formation of VEs should support processes in distributed systems (Parunak, 1995). Moreover, enterprises grouped in a VO should be capable of sharing information, data and maybe, even communicate by means of audio and video. Other characteristics like security, feasibility, human computer interaction and treatment system fails, are also required.

A reasonable number of solutions already exist for this kind of communication infrastructure, however, the investment value varies considerably. In this way, a multinational enterprise, which can afford high investments, is able, for example, to hire satellite channels in order to link its subsidiaries with data, audio and video, located in different countries. Nevertheless, in an even more competitive global market, great part of enterprises is looking for viable solutions of high performance and low costs, especially SMEs that can not afford high investments. The public network Internet enters in this context, as the best solution for this communication infrastructure.

Its disposability almost global and its homogeneous technology justify the Internet success, as an enabler technology. Together these qualities means that any enterprise can connect itself using Internet technology, not only physically, but also on all network layers, which is a key strategy for VEs. For instance, if two systems are connected to the Internet, then, no more is necessary to establish a communication channel between the two systems. This functionality is obtained because of the TCP/IP protocol (Park \& Favrel, 1997).

Based on these characteristics of low costs, flexibility and portability, the Internet technology, by means of its www standard which encapsulate communication protocols to organize and access data, was chosen as the better communication infra-structure for the computer-supported co-operative environment for SMEs participate in VOs. 
Consequently, the Internet communication infra-structure supports the cooperative environment through the technological solutions it can proportionate to some examples of required kind of involvement of the four types of action defined (Table 2).

The first action Generation of New Ideas/Approaches requires some kind of involvement, like critics to ideas without hierarchic influences. This need can be fulfilled by the Internet infrastructure, which can proportionate that the ideas can be published on the internal network for general validation, for instance.

Table 2 - Internet Communication Infra-structure of the Co-operative Environment

\begin{tabular}{|c|c|c|}
\hline $\begin{array}{l}\text { Action Type in a } \\
\text { Distributed } \\
\text { Environment }\end{array}$ & $\begin{array}{l}\text { Examples of Required } \\
\text { Kind of Involvement }\end{array}$ & Technological Benefits \\
\hline $\begin{array}{l}\text { Generation of New } \\
\text { Ideas/ } \\
\quad \text { Approaches }\end{array}$ & $\begin{array}{l}\text { - Critics to ideas without } \\
\text { hierarchic influences }\end{array}$ & $\begin{array}{l}\text { - Ideas can be published on } \\
\text { the internal network for } \\
\text { general validation. }\end{array}$ \\
\hline Project Planing & $\begin{array}{l}\text { - Quick and efficient } \\
\text { dissemination of a final } \\
\text { project information. }\end{array}$ & $\begin{array}{l}\text { - Publish of the required } \\
\text { information in a common } \\
\text { data base with restricted } \\
\text { access to the responsible for } \\
\text { determined functions }\end{array}$ \\
\hline Information Exchange & $\begin{array}{l}\text { - Access to a database about } \\
\text { different topics. }\end{array}$ & $\begin{array}{l}\text { - Access to a common data } \\
\text { base about different topics, } \\
\text { creating consensus and trust } \\
\text { among the team members. }\end{array}$ \\
\hline Problem Solving & $\begin{array}{l}\text { - Broad and efficient } \\
\text { publish of problems to the } \\
\text { people involved and also to } \\
\text { those capable of helping in } \\
\text { the solutions. }\end{array}$ & $\begin{array}{l}\text { - Problems communication } \\
\text { reaches all the responsible } \\
\text { people, possible solutioners } \\
\text { and collaborators to the } \\
\text { resolutions. }\end{array}$ \\
\hline
\end{tabular}

The second type of action is Project Planning, which needs certain types of involvement, as quick and efficient dissemination of a final project information. This requirement can be offered by the Internet infrastructure that can offer benefits, like publish of the required information in a common database with restricted access to the responsible for determined functions, for example.

Information Exchange is the third action that needs, for example, access to a database about different topics. This need can be solved by the Internet infrastructure that can proportionate the access to a common database about different topics, creating consensus and trust among the team members, for instance. 
The fourth and last type of action is the Problems Solving which requires some kind of involvement as: broad and efficient publish of problems to the people involved and also to those capable of helping in the solutions. This requirement can be fulfilled by the Internet infrastructure that can enable that problem communication reaches all the responsible people, possible solutioners and collaborators to the resolutions.

The Internet communication infrastructure offers not only support to the four action types of the co-operative environment, but also works as a platform for the workgroup tools. Moreover, the Internet infrastructure is a technology of simple training, implementation, and use, not requiring considerable modifications or adaptations of the enterprise.

\section{EXEMPLIFICATION SCENARIO}

Today, new teaching techniques are being used in different areas to improve the assimilation of knowledge. These approaches are considered non-conventional since they use active didactics and there is a democratic relationship among the participants. With these techniques, people carry out the process themselves and thus, learn much more.

A new teaching method was developed at the FIM (Model Integrated Factory, USP - São Carlos) to supply the need for people with knowledge in Concurrent Engineering, with a holistic vision approach (Rozenfeld et al., 1998).

FIM has all the elements needed to be an almost completely real environment, that is, it has products, people (characters created with a professional position and responsibilities), shopfloor resources (machines, robots, etc.) and offices.

FIM is a virtual company structured as a collection of Business Processes (BP), such as Marketing, Sales, Product Design and Services and, Production and Delivery for Manufacturing. In order to use these BP as sources of reference for real manufacturing environments, helping them to attain the holistic vision, the BP were mapped out in reference models (Rozenfeld, 1997). Recently, FIM has been engaged in the development of a new Product Development scenario, based on a reference model for a specific type of company (an automotive supplier) and for a sample product.

In this context, a complementary scenario was developed based on the computersupported co-operative environment for SMEs participate in VOs. This scenario will simulate the project of a modular reducer in a complete physically distributed environment. Based on the reference model of VOs, the scenario is inserted in the context of the Global Virtual Business framework, where the FIM is a enterprise that belongs to a Virtual Industry Cluster, whose Virtual Enterprise Broker has a data base of competencies on the Internet, which enables the link with other VEBs.

The reference model's processes range from the conception of a new idea to product validation, including concept and project.

In the Conception phase, the idea for a new product is created, along with its full scope and development schedule. The next phase, Concept, analyses the customer's needs and based on this analysis, the technical expectations are determined. The following activities can now be engaged in: drawings, process planning, make or buy decisions and investment analysis. 
In the Design phase, definitions are made in regard to suppliers, component specifications (shape, dimensions, tolerances and material). The respective process plan (tools, fixtures and quality control) is detailed and the assembly process verified.

In the final phase of development, Product Validation, the prototype and the pilot batch are produced to validate the design and process. Upon conclusion of all the aforementioned activities, the company can begin production.

\subsection{Hypothetical Script}

Part of a hypothetical situation that simulates the development of the new special modular reducer produced at FIM, through a VE, is presented as an example. This small presentation is only part of the product development script, which is composed of acts and scenes, forming the basis for the Product Development Simulation.

\section{Product Conception}

The first part begins with the identification of an opportunity. It is there that, during a visit to some German velocity reducers' manufacturers, Mr. Barganha, the FIM's commercial director, becomes acquainted with the production of a special modular reducer, a new business opportunity for FIM. However, he noticed that FIM alone would not have the required conditions and resources to explore this opportunity. So, he thinks about the necessity of establishing a co-operation, possibly a VE.

He consulted the FIM ideas rank, through the Intranet, and saw that there weren't any related idea to the new opportunity he had identified. So, Mr. Barganha looked for information about this new type of product and its manufacturing, tracing a superficial profile of the possible partners that could participate in this project. Using the Internet, he consulted the VEB, where he could identify the possible partners to explore the opportunity, not only from the FIM's VIC, but also from others VICs.

Using videoconference resources, Mr. Barganha presents his idea for an analysis of product attractiveness to the Marketing Director, Ms. Marta Marquete.

Ms. Marta Marquete analyses the information sent by Mr. Salim Barganha and arranges a meeting with the FIM multifunctional attractiveness analyses team. In the same e-mail message, she includes information on the product and asks each participant to fill out an electronic attractiveness sheet, with the purpose of increasing the meeting's productivity.

The attractiveness analyses will permit a refinement on the requirements of potential partners to the VE formation.

During the meeting with the attractiveness team and the administration, Mr. Barganha participates through videoconference, Ms. Marquete explains Barganhas's idea of producing a new special reducer and presents the possible partners to a VE formation, consolidating the attractiveness analyses. In the end, the administration approves the opportunity exploration by creating a VE.

Based on the meeting decisions, Mr. Barganha and Ms. Marquete, using videoconference select among the possible partners identified, the ones that would 
better fit the requirements of the opportunity exploration and the strategy visualized by FIM.

One of the chosen enterprises is located in Germany, so Mr. Barganha exposes the opportunity to it. The other one selected is located in Brazil, so Ms. Marquete goes personally to expose the opportunity.

Both enterprises agree to participate in a VE to explore the special reducer opportunity. Thus, forming a Global Virtual Enterprise, according to the framework of Global Virtual Business. A meeting among them is arranged.

At this meeting, the creating of the VE is formalized, designing the rights, responsibilities and contributions of each of the three partners. The meeting takes place at FIM, with the participating of the administration and information manager of the other Brazilian partner and, through videoconference, Mr. Barganha and the same staff of the German partner.

During the meeting, using data transfer and application sharing, the partners representatives start to define the full scope and development schedule of the project. They also chose the product coordination among the employees of the three partners to be the responsible of the special modular reducer project. This person will be also in charge of the VE coordination.

The information managers of the three partners agree in a solution for the information systems integration of the three different enterprises. They will use the Internet infrastructure to be the standard protocol of communication.

In this way, an extranet was developed to be not only the platform for the workgroup tools required to the project, but mainly to support the four action types of a cooperative environment.

Some concepts, techniques and tools that are taught in the simulation, are identified in this first part. These are e-mail, videoconference, application sharing, data transfer, attractiveness analysis, multifunctional team, concurrent engineering, value analysis and others.

This example is just a part of the simulation scenario, the whole script is more complete. Nevertheless, the purpose of this example is only to give an idea of how the simulation is done.

\section{Scenario Web Pages}

Following, some web pages of the scenario are presented, in order to characterize the distributed co-operative environment of product development. 
The basic structure of the extranet, called SMR - Special Modular Reducers, was designed exclusively to serve to this specific project (Figure 3). However, this structure can be easily adapted to any project developed in a distributed form.

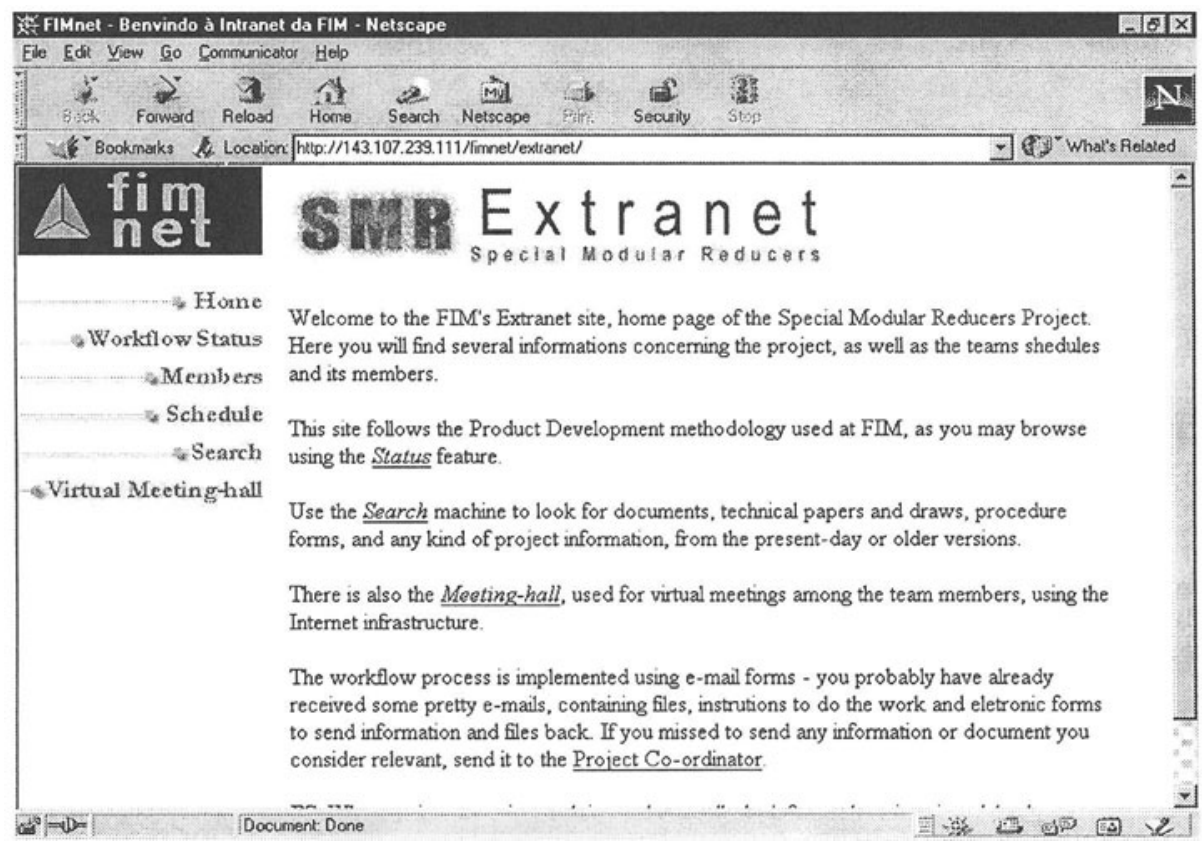

Figure 3 - Extranet Basic Structure of the Co-operative Environment Scenario

The main topics of the extranet are Workflow Status (permits the easy detailed visualization of the whole project, with the status of all the activities); Members (list all the people involved in the VE, with their position in their enterprise and in the VE); Schedule (visualization of the general schedule of the project, verify next meetings or set new ones); Search (functionality to thrive information and data efficiently) and Virtual Meeting Hall (simple alternative solution to make videoconference, based on stream technology).

The videoconference on the web, developed in the Virtual Meeting-Hall section, do not substitute, however, other videoconferences tools, specially, those which aggregate other functionalities like application sharing (Figure 4). The main objective of the Virtual Meeting-Hall section is to optimize the arrangement and configuration of videoconferences, decreasing the quantity of resources necessaries that should be bought, and mainly, configured to each network point that participate in a videoconference.

These functionalities implemented on the extranet basic structure constitute an exemplification of the co-operative environment proposed, by means of the adequate workgroup utilization tools on a specific distributed project type of action. 


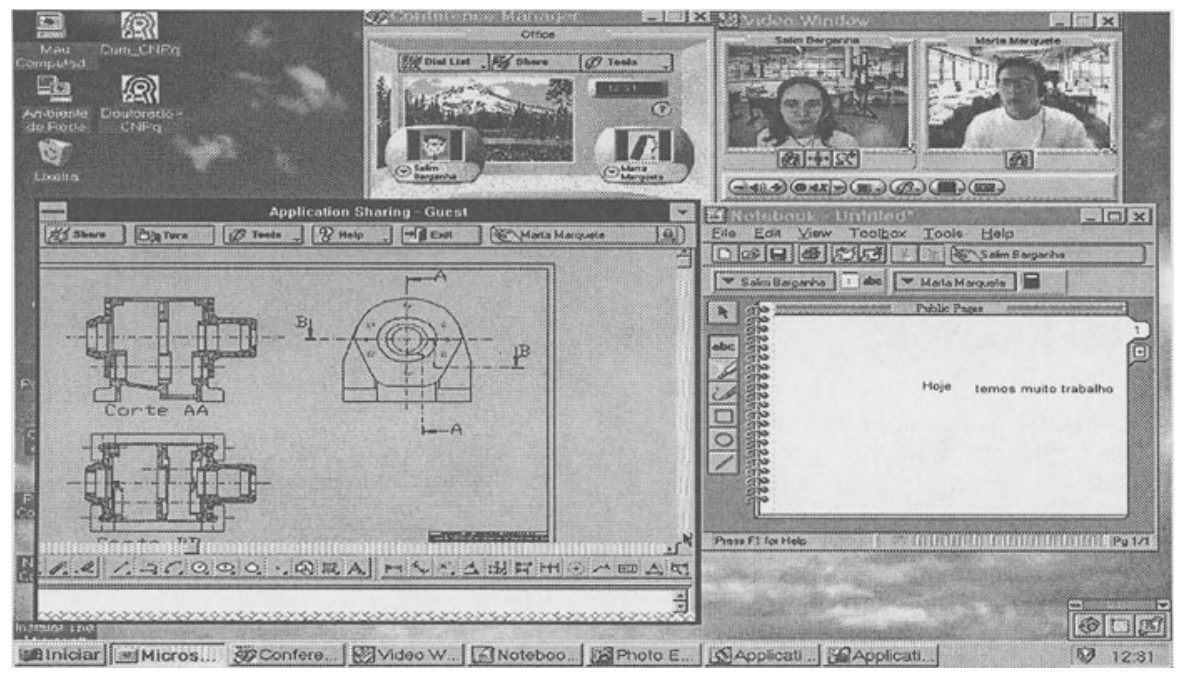

Figure 4 - Example of a Videoconference Tool with Application Sharing

\section{FINAL REMARKS}

The main benefits of this computer-supported co-operative environment for SMEs participate in VOs proposal is the possibility it offers to be an important guide to this class of enterprises, which are adopting or thinking of imple4menting these workgroup tools in order to participate in co-operative networks. That however, work it out today without the required knowledge about the operation form and its implications. Besides this, big enterprises can use the design of this co-operative environment to develop computer-supported co-operations between itself and its suppliers.

That is it, the design of this co-operative environment proportionated a scheme that can be used as a reference to the development of new computer-supported cooperative environments.

Moreover, the importance of VOs as an adequate form of organization for SMEs face the competitive actual market, and the role of workgroup tools that enable their viability, through transaction costs reduction, are formalized.

The elaboration of the exemplification scenario presents an instantiation of the action types of a distributed co-operative environment and the workgroup tools they require as support. This scenario can be used for educational purposes, where it will be possible to the simulation participants carry out the process themselves and thus, learn much more about the workgroup tools functioning in different activities of a distributed project. 


\section{ACKNOWLEDGMENTS}

The author would like to thank the Fundação de Amparo à Pesquisa do Estado de São Paulo - FAPESP - for the financial support during her master research activities.

\section{REFERENCES}

1. Bremer, C., Walz M., Molina A., Eversheim W.. Global Virtual Business - A Systematic Approach For Exploiting Business Opportunities in Dynamic Markets. International Journal of Agile Manufacturing. Vol. 2, Issue 1, 1999.

2. Bremer, C.. Uma Análise da Aplicação do Modelo de Empresas Virtuais na Indústria Brasileira. XVI Encontro Nacional de Engenharia de Produção - Brazil Second Congrees of Industrial Engineering, Universidade Metodista de Piracicaba, Piracicaba, 1996.

3. Byrne, J. A.. Virtual Corporation. Business Week, February 8, 1993.

4. Camarinha-Matos, L., M.; Lima, C.. Configuration and Coordination Issues in a Virtual Enterprise Environment. Proceedings of the Tenth International IFIP WG 5.2/5.3 Conference, Prolamat'98, Trento/Italy, 1998.

5. Coleman, D.. Groupware: The Changing Environment. Collaborative Strategies, Http://www.collaborate.com/publications/section1-7.html , 1996 (20 Jul. 98).

6. Collaborative Strategies. Eletronic Collaboration on the Internet and Intranets. Http://www.collaborate.com/publications/intranet.html , 1996 (20 Jul. 98).

7. Creighton, J. L.; Adams, J. W. R.. Cyber Meeting: How to Link People and Technology in Your Oailrganization. New York, Amacom, 1998.

8. Hamuel, G.; Prahalad, C. K.. Competing for the Future. Boston, 1994.

9. Hardwick, S.. Videoconferencing Accelerates Time to Market. VTEL Corporation, Http://www.vtel.com/vcnews/wpap5.html , 1997 (20 Jul.98).

10. Maaß, S.. Computergesrtütztte Kommunikation und Kooperation. Kooperative Arbeit und Computerunterstützung: Stand und Perspektiven. Verlag für Angewandte Psychologie, Göttingen, p 11-34, 1990.

11. Olson, J.; Teasley, S.. Groupware in the Wild: Lessons Learned from a Year of Virtual Collocation. Proceedings of CSCW'96, Cambridge, 1996.

12. Park, K.H.; Favrel, J.. A Network-centric Information System Infrastructure for Extended or Virtual Enterprises. Conference on Management and Control of Production and Logistics, Campinas/SP Brazil - Set., 1997.

13. Parunak, V.. Technologies for Virtual Enterprises: A Proposal for NIST ATP. Draft. ITI , van@iti.org (2 Out. 97), 1995.

14. Picot, Arnold; Reichwald, Ralf \& Wigand Rolf. "Die Grenzenlose Unternehmung“, Gabler Verlag, 1996.

15. Rozenfeld, H.; Oliveira, C.; Aguiar, A.; Omokawa, R. Development Of A Concurrent Engineering Scenario For Educational Purposes. International Conference On Education In Manufacturing, San Diego, California, 1998.

16. Rozenfeld, H. Desenvolvimento de Produtos na Manufatura Integrada por Computador (CIM). Engineering School of São Carlos, Univeristy of São Paulo. White-paper (http://www.numa.org.br), 1997. 